\title{
Subcortical Glutamate Mediates the Reduction of Short- Range Functional Connectivity with Age in a Developmental Cohort
}

\author{
(1)Carmen Ghisleni, ${ }^{1,2,3}$ @Steffen Bollmann, ${ }^{1,2,3}$ @Simon-Shlomo Poil, ${ }^{1,2}$ Daniel Brandeis, ${ }^{2,3,5,6}$ Ernst Martin, ${ }^{1,2,3}$ \\ (DLars Michels, ${ }^{1,7}$ (D) Ruth L. 0'Gorman, ${ }^{1,2 *}$ and (DPeter Klaver ${ }^{1,2,3,4 *}$ \\ ${ }^{1}$ Center for MR-Research, University Children's Hospital Zurich, Steinwiesstrasse 75, 8032 Zurich, Switzerland, 2Zurich Center for Integrative Human \\ Physiology, University of Zurich, 8057 Zürich, Switzerland, ${ }^{3}$ Neuroscience Center Zurich, University of Zurich and ETH Zurich, 8057 Zurich, Switzerland, \\ ${ }^{4}$ Department of Psychology, University of Zurich, 8050 Zurich, Switzerland, ${ }^{5}$ Department of Child and Adolescent Psychiatry, University of Zurich, 8032 \\ Zurich, Switzerland, ${ }^{\circ}$ Department of Child and Adolescent Psychiatry and Psychotherapy, Central Institute of Mental Health, Medical Faculty Mannheim/ \\ Heidelberg University, 68159 Mannheim, Germany, and ${ }^{7}$ Neuroradiology Clinic, University Hospital Zurich, 8091 Zurich, Switzerland
}

\begin{abstract}
Marked changes in brain physiology and structure take place between childhood and adulthood, including changes in functional connectivity and changes in the balance between main excitatory and inhibitory neurotransmitters glutamate (Glu) and GABA. The balance of these neurotransmitters is thought to underlie neural activity in general and functional connectivity networks in particular, but so far no studies have investigated the relationship between human development related differences in these neurotransmitters and concomitant changes in functional connectivity. $\mathrm{GABA}+/ \mathrm{H}_{2} \mathrm{O}$ and $\mathrm{Glu} / \mathrm{H}_{2} \mathrm{O}$ levels were acquired in a group of healthy children, adolescents, and adults in a subcortical (basal ganglia) region, as well as in a frontal region in adolescents and adults. Our results showed higher GABA + I Glu with age in both the subcortical and the frontal voxel, which were differentially associated with significantly lower $\mathrm{Glu} / \mathrm{H}_{2} \mathrm{O}$ with age in the subcortical voxel and by significantly higher $\mathrm{GABA}+/ \mathrm{H}_{2} \mathrm{O}$ with age in the frontal voxel. Using a seed-to-voxel analysis, we were further able to show that functional connectivity between the putamen (seed) and other subcortical structures was lower with age. Lower subcortical $\mathrm{Glu} / \mathrm{H}_{2} \mathrm{O}$ with age mediated the lower connectivity in the dorsal putamen. Based on these results, and the potential role of Glu in synaptic pruning, we suggest that lower Glu mediates a reduction of local connectivity during human development.
\end{abstract}

Key words: development; functional connectivity; GABA; glutamate; magnetic resonance spectroscopy; working memory

\section{Introduction}

The transition from childhood to adulthood is accompanied by changes in regional gray matter volume, increases in white matter volume (Giedd and Rapoport, 2010), as well as increases in longrange corticocortical networks, and decreases in short-range cortical and subcortical networks (Fair et al., 2007a, 2009; Supekar et al., 2009). Functional network changes in development are likely to be attributed to putative changes in neurotransmitter levels, such as the major inhibitory and excitatory neurotransmitters GABA and glutamate (Glu), respectively. It has been suggested that adjustments of the excitation-inhibition balance on both individual neurons and within networks are accompanied by

\footnotetext{
Received Oct. 21, 2014; revised April 11, 2015; accepted April 14, 2015.

Author contributions: D.B., E.M., L.M., R.L.O., and P.K. designed research; C.G., S.B., and S.-S.P. performed research; C.G., S.B., R.L.O., and P.K. analyzed data; C.G. and P.K. wrote the paper.

This work was supported by the University Research Priority Program "Integrative Human Physiology" and the EMDO Stiftung, Zurich. We thank all participants and their parents for taking part in this study.

The authors declare no competing financial interests.

${ }^{*}$ R.L.O. and P.K. contributed equally to this work.

Correspondence should be addressed to Dr Peter Klaver, Institute of Psychology, Division of Abnormal

Psychology and Clinical Intervention, Binzmühlestrasse 14/17, CH-8050 Zurich, Switzerland. E-mail: p.klaver@psychologie.uzh.ch.

DOI:10.1523/JNEUROSCI.4375-14.2015

Copyright $\odot 2015$ the authors $\quad 0270-6474 / 15 / 358433-09 \$ 15.00 / 0$
}

synaptic elimination during adolescence (Selemon, 2013). The main argument in support of this hypothesis originates from the specificity of loss, i.e., the excitatory synapses are selectively degenerated, whereas inhibitory synapses are spared in primates (Bourgeois and Rakic, 1993). However, the interaction between developmental changes in GABA and Glu, and functional network changes in humans is currently unresolved. GABAergic interneurons not only regulate nearly all key developmental steps in the cortex but also the experience-dependent refinement of local circuits (Di Cristo, 2007), and they play a central role in shaping developing hippocampal networks (Bonifazi et al., 2009). Glu has been linked to synchronizing neuronal networks (Rodriguez et al., 2013). Glu has been reported to be mostly positively associated with functional connectivity (Schmaal et al., 2012; Duncan et al., 2013; Kapogiannis et al., 2013), whereas GABA has been negatively associated with functional connectivity (Kapogiannis et al., 2013; Stagg et al., 2014).

To our knowledge, only one study investigated GABA and Glu in healthy adolescents (12-14 years) in addition to young adults, and reported an increase of GABA and a nonsignificant decrease of Glu with age (Silveri et al., 2013). There are no studies investigating GABA changes in the first years after birth, although a few reports of Glu changes including children and adolescents 
showed steep increases, reaching a plateau in childhood (Blüml et al., 2013; Degnan et al., 2014).

The aim of this study, therefore, was to answer two questions. First, how do GABA and Glu differ between late childhood to middle adulthood in subcortical and cortical regions? Second, do developmental differences in GABA/Glu contribute to age related differences in neural networks? For the first aim, we acquired $\mathrm{GABA}+/ \mathrm{H}_{2} \mathrm{O}$ and $\mathrm{Glu} / \mathrm{H}_{2} \mathrm{O}$ levels in healthy children, adolescents, and adults in a subcortical (basal ganglia) region, as well as in a cortical (frontal) region in adolescents and adults. We focused on these two regions because they follow different developmental trajectories, e.g., in gray matter (Østby et al., 2009) and in microstructural maturation (Lebel et al., 2008). For the second aim, we examined the contributions of the subcortical neurotransmitter levels to the developmental differences of neural networks, assessed by functional connectivity. We expected to find lower $\mathrm{Glu} / \mathrm{H}_{2} \mathrm{O}$ and higher $\mathrm{GABA}+/ \mathrm{H}_{2} \mathrm{O}$ associated with age. We hypothesized that this relative higher GABA+/Glu with age would be related to differences in local (i.e., short-range) and distal (i.e., long-range) connectivity.

\section{Materials and Methods}

Subjects. To investigate developmental differences in the major inhibitory and excitatory neurotransmitter levels, we acquired magnetic resonance spectroscopy (MRS) measures of $\mathrm{GABA}+/ \mathrm{H}_{2} \mathrm{O}$ and $\mathrm{Glu} / \mathrm{H}_{2} \mathrm{O}$ in healthy children, adolescents, and adults during rest in a subcortical (basal ganglia) and in a frontal voxel. MRS values from the subcortical voxel were obtained from a total of 80 subjects. Of these, 40 were adults (21 females) with a mean age of 32.0 years (SD: 9.6; range: $21.0-53.3$ years) and 40 were children and adolescents ( 19 females) with a mean age of 13.0 years (SD: 3.0, range 8.1-18.0 years). The MRS measurement in the frontal voxel was not conducted in one adult subject and only in subjects older than 13 years, resulting in a total of 56 subjects. Of these, 39 were adults ( 21 females) with a mean age of 32.0 years (SD: 9.7; range: 21-53.3 years) and 17 adolescents ( 9 females) with a mean age of 16 years (SD: 1.4 ; range: $13.6-18.0$ years).

After MRS measurement participants performed a spatial working memory task. Task functional magnetic resonance imaging (fMRI) data were obtained from all children and adolescents and from a subset of adults, resulting in a total of 65 subjects. Of these, 25 were adults (15 females) with a mean age of 32.8 years (SD: 9.7; range: $21.0-50.6$ years). The numbers for children and adolescents remained as stated above for the MRS values. Due to the smaller numbers of subjects for the task fMRI data and MRS measurements in the frontal voxel, we restricted our analysis on the relationship between age related differences in functional connectivity and MRS measurements to the subcortical voxel. No current neurological or psychiatric illness of the subjects was reported by them or their parents, respectively. All subjects gave written informed consent before the experiment. The study was approved by the Ethics Committee of the Canton of Zurich, Switzerland.

MRI data acquisition. MRI data were acquired with a 3.0 T GE HD.xt whole-body MRI scanner (GE Healthcare), using an 8-channel receiveonly head coil and a body transmit coil. The MRI protocol included a 3D T1-weighted gradient echo pulse sequence [number of slices $=172$, slice thickness $(\mathrm{ST})=1.0 \mathrm{~mm}$, repetition time $(\mathrm{TR})=9.94 \mathrm{~ms}$, echo time $(\mathrm{TE})=2.948 \mathrm{~ms}$, inversion time $=600 \mathrm{~ms}$, field-of-view $(\mathrm{FOV})=256$ $\mathrm{mm} \times 192 \mathrm{~mm}$, flip angle $=8^{\circ}$, matrix $=256 \times 192$, reconstructed voxel resolution: $1 \times 1 \times 1 \mathrm{~mm}$ ] used for positioning of the MRS voxels. GABA-edited MR spectra were acquired using the MEGA-PRESS method (Edden and Barker, 2007) with TE $=68 \mathrm{~ms}$, TR $=2000 \mathrm{~ms}, 320$ averages (160 pairs), and an eight-step phase cycle. We acquired spectra from a $28 \times 40 \times 25 \mathrm{~mm}^{3}$ voxel in a left subcortical region centered on the axial slice where the putamen was the widest, with the anterior border of the voxel aligned with the anterior margin of the putamen (Fig. 1, top row, insets). As estimated in native space, this approach shows the putamen comprising between 15 and $29 \%$ of the corresponding MRS voxel (mean $21.7 \%, \mathrm{SD}=2.9$ ). The frontal voxel was $25 \times 40 \times 30 \mathrm{~mm}^{3}$ in size and was positioned as described by Michels et al. (2012). The voxel was centered on the axial slice $1 \mathrm{~mm}$ above the superior margin of the left lateral ventricle. The length of the midline was measured on this slice and the center of the voxel along the anterior-posterior direction was placed at a point $1 / 3$ of the distance down the midline from the anterior margin of the brain and along the left-right direction at a point $1 / 2$ of the distance between the midline and the left lateral border of the brain, perpendicular to the midline (Fig. 1, bottom row, insets). During MRS measurements, subjects were instructed to relax but stay awake. Subsequently, fMRI images were acquired interleaved in 35 axial slices covering the whole brain with a multislice echoplanar imaging sequence (ST $=3 \mathrm{~mm}$; $0.3 \mathrm{~mm}$ skip; 35 slices; $\mathrm{TR}=1.925 \mathrm{~s}$; $\mathrm{TE}=32 \mathrm{~ms}$; flip angle $=74^{\circ}$; matrix $=64 \times 64 ; \mathrm{FOV}=240 \mathrm{~mm}$ ).

fMRI task. We investigated functional connectivity related to spontaneous background activity (Fox et al., 2006; Fox and Raichle, 2007; Norman-Haignere et al., 2012) during a spatial working memory task. The task consisted of a display of 11 circles positioned on a circular grid. Either two or four of the stimulus circles were filled to indicate the positions to be memorized during three different retention intervals $(2,4$, and $6 \mathrm{~s}$, varying from trial to trial). In the subsequent probe phase of each trial, a question mark was shown in one of the 11 circles and subjects indicated by a button press (LuminaBox) whether or not that circle had been filled. The task lasted $14 \mathrm{~min}$ and contained 72 trials in total, with one-half of the trials showing two positions to memorize, and one-half with four (at most 2 trials with the same number in succession). Null trials were included (fixation cross for 2, 4, and $6 \mathrm{~s}$ ) after four trials and motivation trials after 12 trials, displaying the number of correctly answered trials and a smile. The task was implemented in Presentation v16 (Neurobehavioral Systems) and synchronized to the fMRI acquisition. During the MRI acquisition, the task was projected onto a screen at the foot of the MR table, which subjects viewed via a mirror.

MRS analysis. T1-weighted images were segmented in native space using SPM8 with the "New Segment" module (Wellcome Department of Cognitive Neurology, London, UK) running in MATLAB 2012b (MathWorks) to correct the MRS results for partial volume CSF contamination and different water compartment relaxation times (Gasparovic et al., 2006). Metabolite relaxation corrections were performed using published values for the T1 and T2 relaxation times (Träber et al., 2004; Zaaraoui et al., 2007), according to the method detailed in the LCModel manual (LCModel v6.3-1K). The spectra were coil combined with weighting factors derived from the first point of the free induction decay signal from the unsuppressed water lines acquired with each coil. Waterscaled metabolite concentrations were derived with LCModel v6.3-1B (Provencher, 1993). Spectra were frequency aligned to account for frequency drift due to motion or other factors and separated into the edited (subtraction) spectra and the edit OFF subspectra. The edited spectra were analyzed with a simulated basis set including basis spectra for GABA, glutathione (GSH), $N$-acetylaspartate (NAA), glutamine (Gln), Glu, and $N$-acetylaspartylglutamate (NAAG; Fig. 1). The edit OFF subspectra were analyzed with a simulated basis set including basis spectra for NAA, NAAG, creatine (Cr), choline (Cho), Glu, Gln, GSH, GABA, lactate, and myo-inositol. GABA findings described subsequently are reported as GABA + due to the contribution of a macromolecular component to the edited peak at $3 \mathrm{ppm}$ in the assessment of GABA with MEGA-PRESS. GABA $+/ \mathrm{H}_{2} \mathrm{O}$ and $\mathrm{Glu} / \mathrm{H}_{2} \mathrm{O}$ were quantified from the edited spectra, using the control parameter sptype $=$ ' mega-press -2 ' . The Cramer Rao lower bound (CRLB) of the spectral fit for all GABA $+/ \mathrm{H}_{2} \mathrm{O}$ and $\mathrm{Glu} / \mathrm{H}_{2} \mathrm{O}$ values were $<20 \%$ for all participants (Table 1 ). However, due to the spectral dispersion at $3 \mathrm{~T}$ the derived $\mathrm{Glu} / \mathrm{H}_{2} \mathrm{O}$ concentrations may also include small contributions from $\mathrm{Gln} / \mathrm{H}_{2} \mathrm{O}$. The linewidth reported by LCModel ranged from 0.038 to $0.129 \mathrm{ppm}(4.85-16.5 \mathrm{~Hz})$ in the subcortical voxel, and from 0.029 to $0.067 \mathrm{ppm}(3.7-8.6 \mathrm{~Hz})$ in the frontal voxel for all participants (Table 1 ). Because particularly younger participants might move during MRS measurements, we estimated an individual motion parameter from the fMRI data. This "fingerprint" was estimated by calculating the mean and SD of distances from scan to scan across all scans in each individual and separately for translation and rotation realignment parameters resulting in a mean and SD distance for translation parameters, and mean and SD distance for rotation parame- 

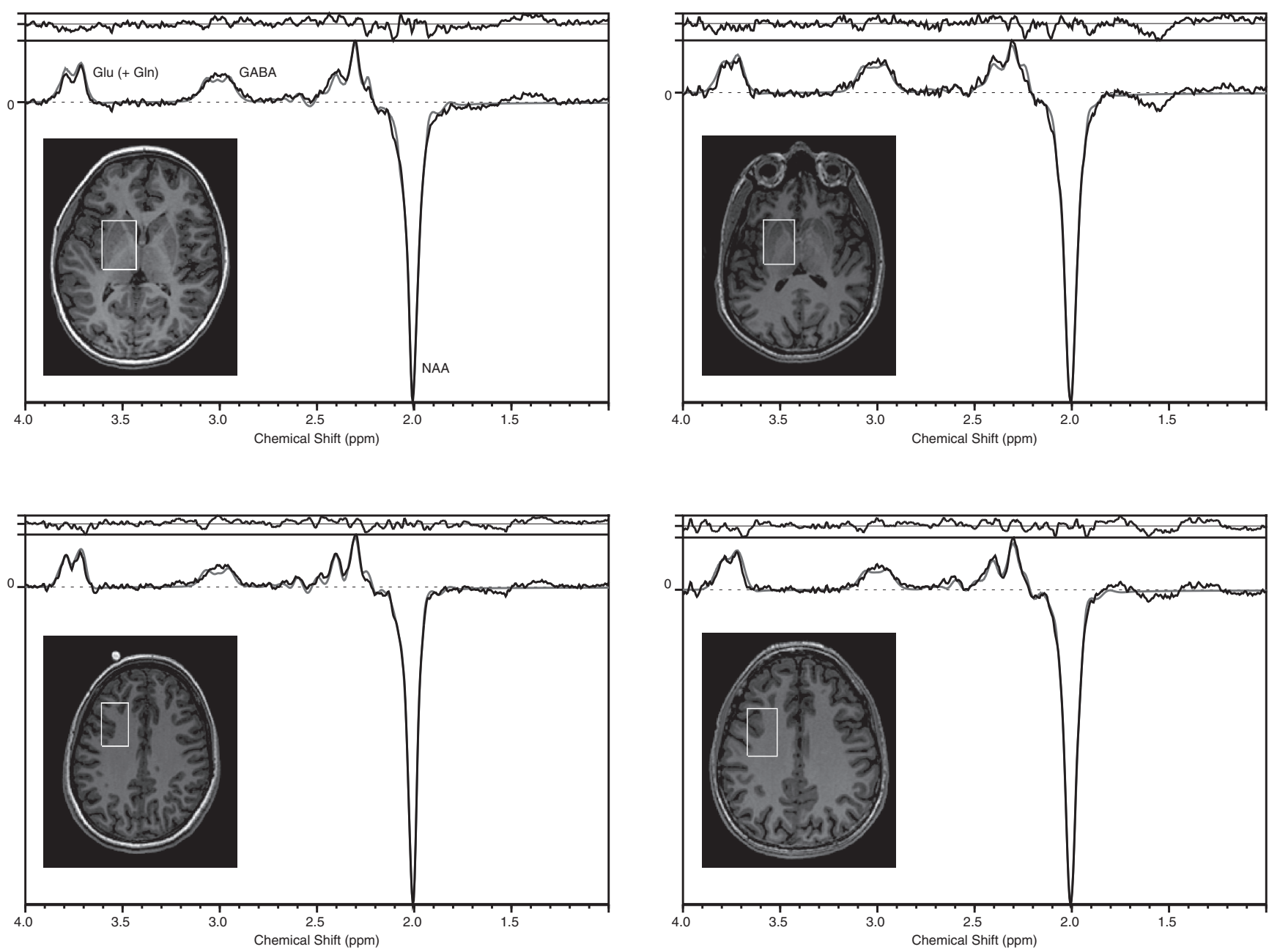

Figure 1. Examples of voxel positions and edited spectral fits in the left subcortical region (top row) of a child (9 years, left) and an adult subject (41 years, right), and in the left frontal region (bottom row) of an adolescent (15 years, left) and an adult subject (41 years, right). Spectra are shown in black, with the spectral fits overlaid in gray. The residuals are shown above each spectrum. Glu $(+G \ln )$, glutamate with contributions from glutamine.

ters. Next, the SD/mean distance was averaged between translation and rotation parameters. These fingerprints were used to statistically control the associations between metabolites and age for movement.

Statistical analyses. Correlations (Spearman's $r_{s}$ ) between age and MRS values $\left(\mathrm{Glu} / \mathrm{H}_{2} \mathrm{O}, \mathrm{GABA}+/ \mathrm{H}_{2} \mathrm{O}, \mathrm{GABA}+/ \mathrm{Glu}\right)$ are reported. All statisti$\mathrm{cal}$ analyses (not including the functional connectivity analyses) were performed in IBM SPSS Statistics v20, and the plots were created using R (v3.1.0; ggplot from the ggplot2 package). We report data before and after Bonferroni correction $(p<0.0125)$.

Functional connectivity analyses. Functional connectivity was assessed with the conn toolbox v14.c (Whitfield-Gabrieli and Nieto-Castanon, 2012) using standard fMRI preprocessing. Spatial preprocessing of the task fMRI data included slice-timing correction, motion correction, coregistration of functional volumes to the anatomical volumes, and smoothing with a Gaussian filter of $8 \mathrm{~mm}$. The voxel size for analyses was $2 \mathrm{~mm}$. T1-weighted anatomical volumes were segmented into gray matter, white matter, and CSF and the resulting transformation parameters were used to normalize the anatomical and functional images. These preprocessed images were further bandpass filtered $(0.01-0.1 \mathrm{~Hz})$, and non-neuronal contributions from white matter and CSF were regressed out (5 principle components) at the subject level using the aCompCor strategy (Behzadi et al., 2007) implemented in the conn toolbox. Additionally, each subject's realignment parameters ( 3 translation, 3 rotation parameters, and their first temporal derivates) were included as confounding factors. Finally, event-related task effects were also regressed out with five regressors (and their first temporal derivatives) consisting of two regressors modeling the retention phase with different durations of correctly answered trials (starting from stimulus onset and lasting until probe onset) for the two- and the four-circle trials, respectively, two regressors modeling the retrieval phase of correctly answered trials (starting from probe onset and lasting until button press) for the two- and the four-circle trials, respectively, and one regressor modeling all button presses (duration of $0 \mathrm{~s}$ ). This approach of analyzing functional connectivity from residuals of the entire time courses of event-related task fMRI data was described by Fair et al. (2007b) and applied by several studies (Harris et al., 2011; Zhang et al., 2014). These spontaneous correlations are meaningful and may help characterize the systems level interactions subserving cognitive processes (Norman-Haignere et al., 2012). Because the MRS subcortical voxel was centrally placed on the left putamen, this region was chosen as the seed region for the connectivity analyses. The region of interest was taken from the Harvard-Oxford Subcortical Structural Atlas available in FSL (http://fsl.fmrib.ox.ac.uk/fsl/fslwiki/). The average blood oxygen level-dependent (BOLD) time series was computed across all the voxels within the left putamen and used for the seed-to-voxel (whole brain) bivariate correlation analyses. For second level analyses, i.e., regression models with age and the MRS values as between-subject effects, a Fisher transformation (inverse hyperbolic tangent function) was applied to the correlation measures to improve the normality assumptions of standard second-level general linear models (Whitfield-Gabrieli and Nieto-Castanon, 2012). Separate regression models were run in the conn toolbox across all available subjects to evaluate the association between seed-to-voxel connectivity (left putamen as seed) and the variables age and the different MRS values (Glu/ $\mathrm{H}_{2} \mathrm{O}, \mathrm{GABA}+/ \mathrm{H}_{2} \mathrm{O}, \mathrm{GABA}+/ \mathrm{Glu}$ from the subcortical voxel) as 
Table 1. Metabolite concentrations, CRLB, linewidths, and voxel tissue composition

\begin{tabular}{|c|c|c|c|c|}
\hline & \multicolumn{2}{|c|}{ Subcortical voxel } & \multicolumn{2}{|l|}{ Frontal voxel } \\
\hline & $<25$ years & $>25$ years & $<25$ years & $>25$ years \\
\hline$n$ ( $n$ females) & $51(25)$ & $29(15)$ & $28(15)$ & $28(15)$ \\
\hline Age & $15.1(4.8)$ & $35.6(8.9)$ & $18.5(3.5)$ & $35.6(9.1)$ \\
\hline \multicolumn{5}{|l|}{ MEGA-PRESS } \\
\hline $\mathrm{GABA}+/ \mathrm{H}_{2} \mathrm{O}(\mathrm{mM})$ & $1.9(0.2)$ & $1.9(0.2)$ & $1.4(0.1)$ & $1.5(0.2)$ \\
\hline $\mathrm{GABA}+/ \mathrm{H}_{2} \mathrm{O}$ CRLB (\%) & $3.5(0.6)$ & $3.9(1.0)$ & $4.6(0.9)$ & $4.4(0.9)$ \\
\hline $\mathrm{Glu} / \mathrm{H}_{2} \mathrm{O}(\mathrm{mm})$ & $4.2(0.5)$ & $3.7(0.5)$ & $3.7(0.4)$ & $3.7(0.3)$ \\
\hline $\mathrm{Glu} / \mathrm{H}_{2} \mathrm{O}$ CRLB (\%) & $4.1(1.0)$ & $5.3(1.9)$ & $3.8(1.2)$ & $4.0(0.9)$ \\
\hline $\mathrm{G} \ln / \mathrm{H}_{2} \mathrm{O}(\mathrm{mm})^{*}$ & $1.3(0.5)$ & $1.7(0.7)$ & $1.0(0.3)$ & $1.1(0.3)$ \\
\hline $\mathrm{Gln} / \mathrm{H}_{2} \mathrm{OCRLB}(\%)^{*}$ & $15.3(2.8)$ & $16.2(2.1)$ & $13.9(3.1)$ & $14.4(2.7)$ \\
\hline $\mathrm{NAA} / \mathrm{H}_{2} \mathrm{O}(\mathrm{mm})$ & $8.9(0.5)$ & $9.1(0.5)$ & $8.2(0.4)$ & $8.4(0.4)$ \\
\hline $\mathrm{NAA} / \mathrm{H}_{2} \mathrm{O}$ CRLB (\%) & $1.0(0.3)$ & $1.0(0.2)$ & $1.1(0.3)$ & $1.1(0.3)$ \\
\hline \multicolumn{5}{|l|}{ PRESS } \\
\hline $\mathrm{Cr} / \mathrm{H}_{2} \mathrm{O}(\mathrm{mm})$ & $5.3(0.9)$ & $5.2(0.6)$ & $5.0(0.5)$ & $5.4(0.3)$ \\
\hline $\mathrm{Cr} / \mathrm{H}_{2} \mathrm{O} \mathrm{CRLB}(\%)$ & $1.9(0.2)$ & $2.0(0.3)$ & $2.0(0.2)$ & $1.9(0.3)$ \\
\hline $\mathrm{Cho} / \mathrm{H}_{2} \mathrm{O}(\mathrm{mm})$ & $0.6(0.1)$ & $0.6(0.1)$ & $0.7(0.1)$ & $0.7(0.1)$ \\
\hline $\mathrm{Cho} / \mathrm{H}_{2} \mathrm{O}$ CRLB (\%) & $2.2(0.4)$ & $2.3(0.5)$ & $2.1(0.3)$ & $2.1(0.3)$ \\
\hline Linewidth (Hz) & $8.0(2.2)$ & $9.4(1.9)$ & $5.9(1.0)$ & $6.7(1.1)$ \\
\hline Grey matter (\%) & $54.0(4.9)$ & $50.8(3.0)$ & $35.8(3.4)$ & $33.2(3.1)$ \\
\hline White matter (\%) & $42.6(3.8)$ & $44.8(2.6)$ & $61.2(4.3)$ & $62.6(4.0)$ \\
\hline Cerebrospinal fluid (\%) & $3.3(3.0)$ & $4.3(1.4)$ & $2.7(1.5)$ & $4.0(2.3)$ \\
\hline Grey/white matter ratio & $1.3(0.2)$ & $1.1(0.1)$ & $0.6(0.1)$ & $0.5(0.1)$ \\
\hline
\end{tabular}

Values are mean (SD).

*Only values considered with CRLB of Gln $<20 \%$ (subcortical voxel: $n=30$ for $<25$ years and $n=14$ for $>25$ years; frontal voxel: $n=25$ for $<25$ years and $n=21$ for $>25$ years).

between-subject effects. Using the same event-related task effects in a separate SPM8 analysis, we verified whether the putamen was active during the task and found strong activity during probe recognition and button press, but not during the retention phase (data not shown). Reported functional connectivity results survived a height threshold of $p<$ 0.001 (uncorrected) and an extent threshold of familywise errorcorrected $p<0.05$ at the cluster level.

As mentioned in the subject section, group sizes for different analyses varied due to differences in available data per subject. A summary of the numbers for the respective analyses is provided here: correlation between age and MRS values from the subcortical voxel: age range $=8.1-53.3$ years; $n=80$, 40 females; correlation between age and MRS values from the frontal voxel: age range $=13.6-53.3$ years; $n=56$, 30 females; regressions of functional connectivity by age and functional connectivity by MRS values from the subcortical voxel: age range $=8.1-50.6$ years; $n=65,34$ females.

\section{Results}

\section{Correlations MRS values with age}

In the subcortical voxel (Fig. 2, top row), a negative correlation between $\mathrm{Glu} / \mathrm{H}_{2} \mathrm{O}$ and age was observed $\left(r_{s}=-0.61, p<0.001\right.$, left), whereas the correlation between $\mathrm{GABA}+/ \mathrm{H}_{2} \mathrm{O}$ and age was not significant $\left(r_{s}=-0.07, p=0.55\right.$, middle). GABA $+/ \mathrm{Glu}$ showed a positive correlation with age $\left(r_{s}=0.58, p<0.001\right.$, right). The negative correlation between $\mathrm{Glu} / \mathrm{H}_{2} \mathrm{O}$ and age remained significant after correction for sex $(r=-0.54, p<$ $0.001)$. The correlation also remained significant if we excluded subjects that had $2 \mathrm{SD}$ more or less than average $\mathrm{Glu} / \mathrm{H}_{2} \mathrm{O}(3$ outliers: $\left.r_{s}=-0.58, p<0.001\right)$. Because the Glu and Gln multiplets partially overlap at $3 \mathrm{~T}$, we reran the $\mathrm{Glu} / \mathrm{H}_{2} \mathrm{O}$ correlations with age only in cases where $\mathrm{Gln} / \mathrm{H}_{2} \mathrm{O}$ was fit with a CRLB $<20 \%$, and the correlation remained significant in the subcortical voxel $\left(r_{s}=-0.64, p<0.001\right)$. We additionally repeated and confirmed the correlation between age and $\mathrm{Glu} / \mathrm{H}_{2} \mathrm{O}$ from this region for participants with linewidth values $<12 \mathrm{~Hz}\left(n=73, r_{s}=-0.61\right.$, $p<0.001)$. Because our sample included subjects younger and older than 25 years of age, one might consider that age related differences might not be related to development. We therefore reran the analyses in the group of younger subjects ( $<25$ years) and older subjects $(>25$ years; Table 1 shows the number of subjects). These analyses replicated that $\mathrm{Glu} / \mathrm{H}_{2} \mathrm{O}$ significantly correlated with age in the younger group $\left(r_{s}=-0.58, p<0.001\right)$ and showed a trend to significance in the age group $>25$ years $\left(r_{s}\right.$ $=-0.36, p=0.054)$. For $\mathrm{GABA}+/ \mathrm{H}_{2} \mathrm{O}$ we found a weak negative correlation with age $<25$ years that was not significant after Bonferroni correction $\left(r_{s}=-0.28, p=0.045\right)$ and no significant correlation $>25$ years $\left(r_{s}=0.09, p=0.629\right)$. These results thus support the notion that the association between $\mathrm{Glu} / \mathrm{H}_{2} \mathrm{O}$ and age was prominent during development. Indeed when comparing regression models we found that logarithmic model slightly better explained the association between age and $\mathrm{Glu} / \mathrm{H}_{2} \mathrm{O}$ than the linear model $\left(R^{2}=0.34\right.$ vs 0.29 , both $\left.p<0.001\right)$. Finally, because particularly younger subjects might move during MRS measurements, we reanalyzed the MRS data after controlling for motion (as described in the Materials and Methods). These analyses led to similar results, such that the correlation between $\mathrm{Glu} / \mathrm{H}_{2} \mathrm{O}$ and age was significant $(r=-0.47, p<0.001)$.

In the frontal voxel (Fig. 2, bottom row), the correlation between $\mathrm{Glu} / \mathrm{H}_{2} \mathrm{O}$ and age was not significant $\left(r_{s}=-0.18, p=0.18\right.$, left), whereas a positive correlation between $\mathrm{GABA}+/ \mathrm{H}_{2} \mathrm{O}$ and age was observed that was not significant after Bonferroni correction $\left(r_{s}=0.30, p=0.02\right.$, middle). GABA $+/$ Glu also showed a positive correlation with age $\left(r_{s}=0.42, p=0.001\right.$, right $)$. The correlation between $\mathrm{GABA}+/ \mathrm{H}_{2} \mathrm{O}$ and age remained significant after controlling for $\operatorname{sex}(r=0.32, p=0.019)$ and the correlation showed a trend to significance after excluding subjects who had 2 SD more or less than average GABA $+/ \mathrm{H}_{2} \mathrm{O}$ ( 3 outlier: $r_{s}=0.25$, $p=0.068$ ). When analyzing younger and older groups separately, we found no significant correlation between $\mathrm{GABA}+/ \mathrm{H}_{2} \mathrm{O}$ and age and between $\mathrm{Glu} / \mathrm{H}_{2} \mathrm{O}$ and age. Finally, we reanalyzed the MRS data after controlling for motion, which led to similar results, such that the correlation between $\mathrm{GABA}+/ \mathrm{H}_{2} \mathrm{O}$ and age was significant ( $r=0.37, p=0.018)$. Together these results indicate that the correlation between $\mathrm{GABA}+/ \mathrm{H}_{2} \mathrm{O}$ and age in the frontal voxel was relatively weak and would not survive correction for multiple comparisons. By contrast, the correlation between $\mathrm{Glu} / \mathrm{H}_{2} \mathrm{O}$ and age in the subcortical voxel was highly robust and would survive multiple comparisons.

Correlations functional connectivity with age and MRS values Figure 3 and Table 2 illustrate the results of the correlation analyses of functional connectivity with age and MRS values.

Age

The functional connectivity showed a negative correlation with age in a cluster encompassing the left putamen and neighboring regions, i.e., left pallidum, thalamus, amygdala, hippocampus, and parahippocampal gyrus (Fig. 3, first row).

\section{$M R S$ values from the subcortical voxel}

A negative correlation between $\mathrm{Glu} / \mathrm{H}_{2} \mathrm{O}$ and functional connectivity was observed in a cluster encompassing the left ventral putamen and orbitofrontal cortex (Fig. 3, second row, blue). This cluster did not overlap with the above-mentioned cluster correlating negatively with age. A positive correlation between Glu/ $\mathrm{H}_{2} \mathrm{O}$ and functional connectivity was observed in a cluster encompassing the left dorsal putamen and adjacent external capsule (Fig. 3, second row, red). This cluster largely overlapped with the above-mentioned cluster correlating negatively with age (Fig. 3 , third row, yellow). Several other regions that correlated with 

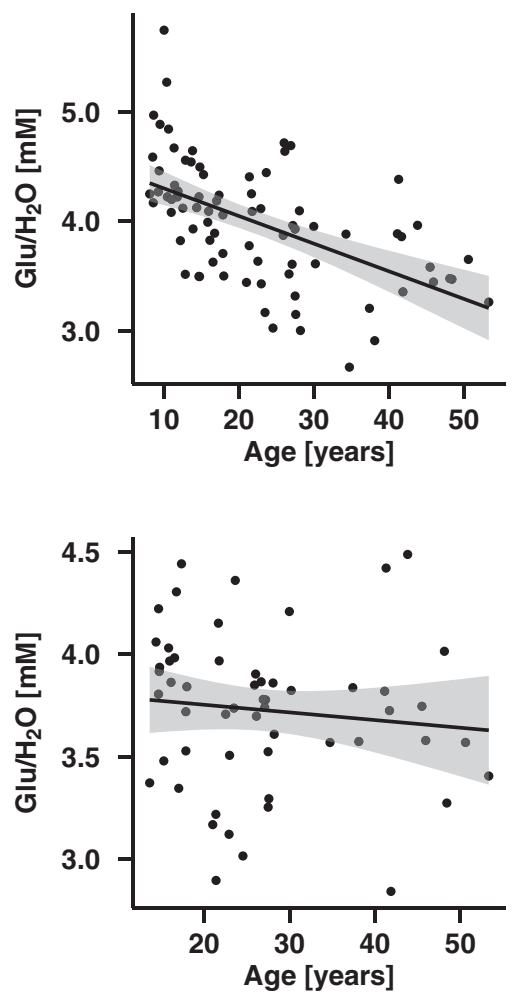
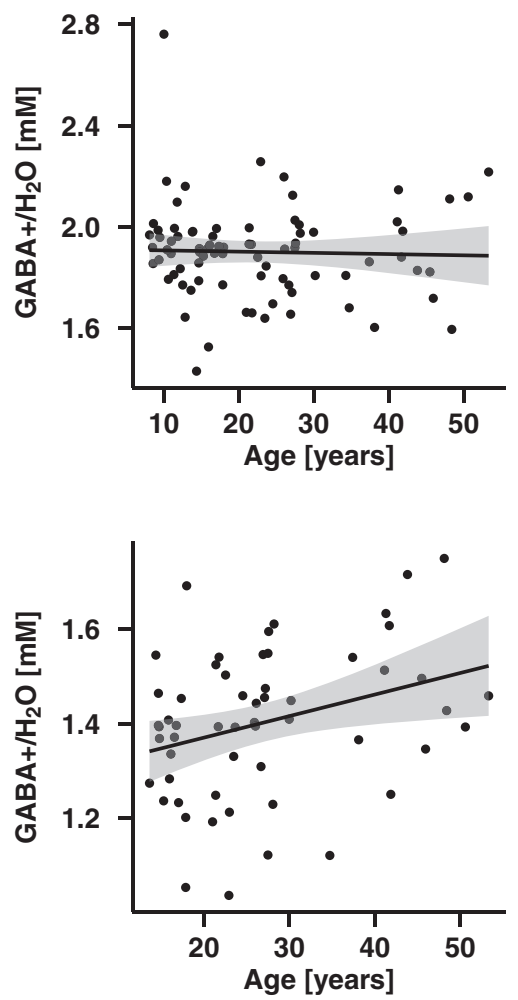
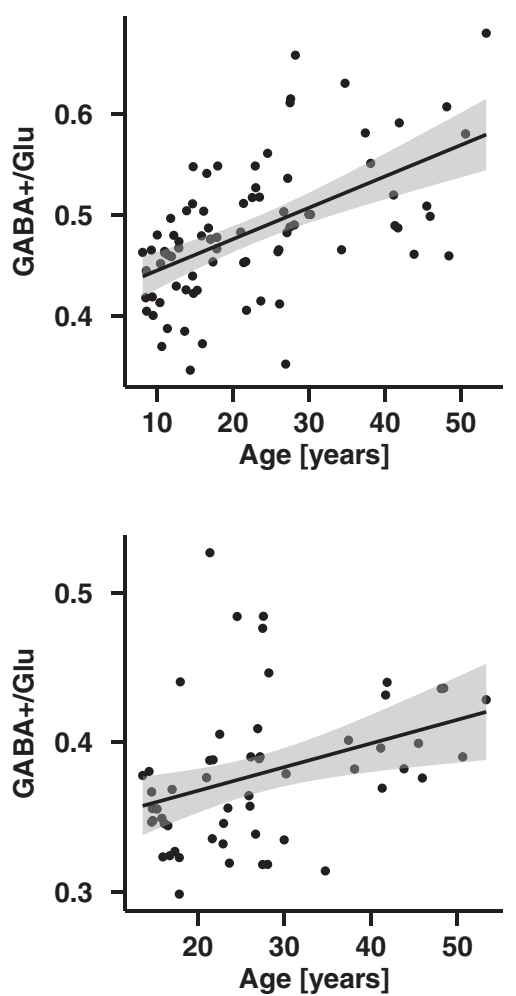

Figure 2. Spectroscopic measures in the subcortical voxel (top row) and the frontal voxel (bottom row) are differentially correlated with age. Glu/ $\mathrm{H}_{2} \mathrm{O}$ (left column) showed a significant decrease with age in the subcortical region $\left(r_{s}=-0.61, p<0.001\right.$; not significant in the frontal region, $r_{s}=-0.18, p=0.18$ ). GABA $+/ \mathrm{H}_{2} \mathrm{O}$ (middle column) showed a significant increase with age in the frontal region $\left(r_{s}=0.30, p=0.02\right.$; not significant in the subcortical region, $\left.r_{s}=-0.07, p=0.55\right) . \mathrm{GABA}+/ \mathrm{Glu}$ (right column) showed a significant increase with age in both regions $\left(r_{s}=0.58\right.$, $p<0.001$ for the subcortical region and $r_{s}=0.42, p=0.001$ for the frontal region).

age, e.g., thalamus and pallidum, showed no significant correlation with $\mathrm{Glu} / \mathrm{H}_{2} \mathrm{O}$. No significant correlation between GABA+/ $\mathrm{H}_{2} \mathrm{O}$ and functional connectivity was observed. GABA+/Glu values correlated negatively with functional connectivity in a cluster encompassing the left dorsal putamen and adjacent external capsule (Fig. 3, fourth row). Because the colocalization between age related changes in connectivity and $\mathrm{Glu} / \mathrm{H}_{2} \mathrm{O}$ related changes in connectivity suggested a $\mathrm{Glu} / \mathrm{H}_{2} \mathrm{O}$ mediated change in connectivity with age, we tested the mediation by a correlation between age and putamen connectivity after controlling for Glu/ $\mathrm{H}_{2} \mathrm{O}$. The results showed that the correlation between age and connectivity remained significant in all regions except for the dorsal putamen, indicating that the connectivity with the dorsal putamen was mediated by age related changes in $\mathrm{Glu} / \mathrm{H}_{2} \mathrm{O}$. Similar results were found when we controlled for the GABA+/Glu ratio. Because male and female subjects might show different patterns of connectivity depending on metabolites and age, we repeated the analyses after statistically controlling for sex. These analyses provided similar results (data not shown). We also tested whether younger $(<25$ years) or older participants ( $>25$ years) might drive age and $\mathrm{Glu} / \mathrm{H}_{2} \mathrm{O}$ associations with putamen connectivity. Here we found both age and $\mathrm{Glu} / \mathrm{H}_{2} \mathrm{O}$ correlations with putamen connectivity in younger participants only (data not shown), which highlighted connectivity with the dorsal putamen to be sensitive to lower $\mathrm{Glu} / \mathrm{H}_{2} \mathrm{O}$ during development.

\section{Discussion}

As hypothesized, age was negatively correlated with $\mathrm{Glu} / \mathrm{H}_{2} \mathrm{O}$ in the subcortical voxel, and positively correlated with GABA+/ $\mathrm{H}_{2} \mathrm{O}$ in the frontal voxel, resulting in a positive association between the GABA+/Glu ratio and age in both regions. The observed age-related changes in $\mathrm{Glu} / \mathrm{H}_{2} \mathrm{O}$ fosters reports that Glu correlates negatively with age in the basal ganglia (Chang et al., 2009), but not in the frontal cortex (Sailasuta et al., 2008; Chang et al., 2009). The positive correlation between $\mathrm{GABA}+/ \mathrm{H}_{2} \mathrm{O}$ and age in the frontal cortex, but not in other regions, concords with studies in adolescents and adults (Silveri et al., 2013; Gaetz et al., 2014). These results might thus support region specific and functionally distinct developmental trajectories of Glu and GABA. Glu might be associated with pruning of subcortical gray matter and concurrent rewiring of gray matter structures (Lebel et al., 2008), whereas GABA links to myelination of frontal white matter trajectories by controlling oligodendrocyte precursor cell activity (Vélez-Fort et al., 2012). Pruning takes place at the synaptic level, and would not be measurable using macroscopic morphometry measurements (Bourgeois and Rakic, 1993; Paus et al., 2008). Yet, further studies are necessary to associate gray and white matter changes with Glu and GABA levels across the full developmental trajectory. Together, this study first reports that developmental changes of Glu and GABA levels depend on both the region and neurotransmitter investigated.

Functional connectivity in the dorsal putamen correlated positively with subcortical $\mathrm{Glu} / \mathrm{H}_{2} \mathrm{O}$ and negatively with age. We propose that $\mathrm{Glu} / \mathrm{H}_{2} \mathrm{O}$ mediates the negative association between local functional connectivity in the dorsal putamen and development. In support of this notion, the correlation between functional connectivity and age disappeared after controlling for Glu/ $\mathrm{H}_{2} \mathrm{O}$ levels. Glu has previously been positively (Schmaal et al., 2012; Duncan et al., 2013; Kapogiannis et al., 2013) and negatively associated with functional connectivity (Duncan et al., 2013), depending on the target region of interest. Our finding of 

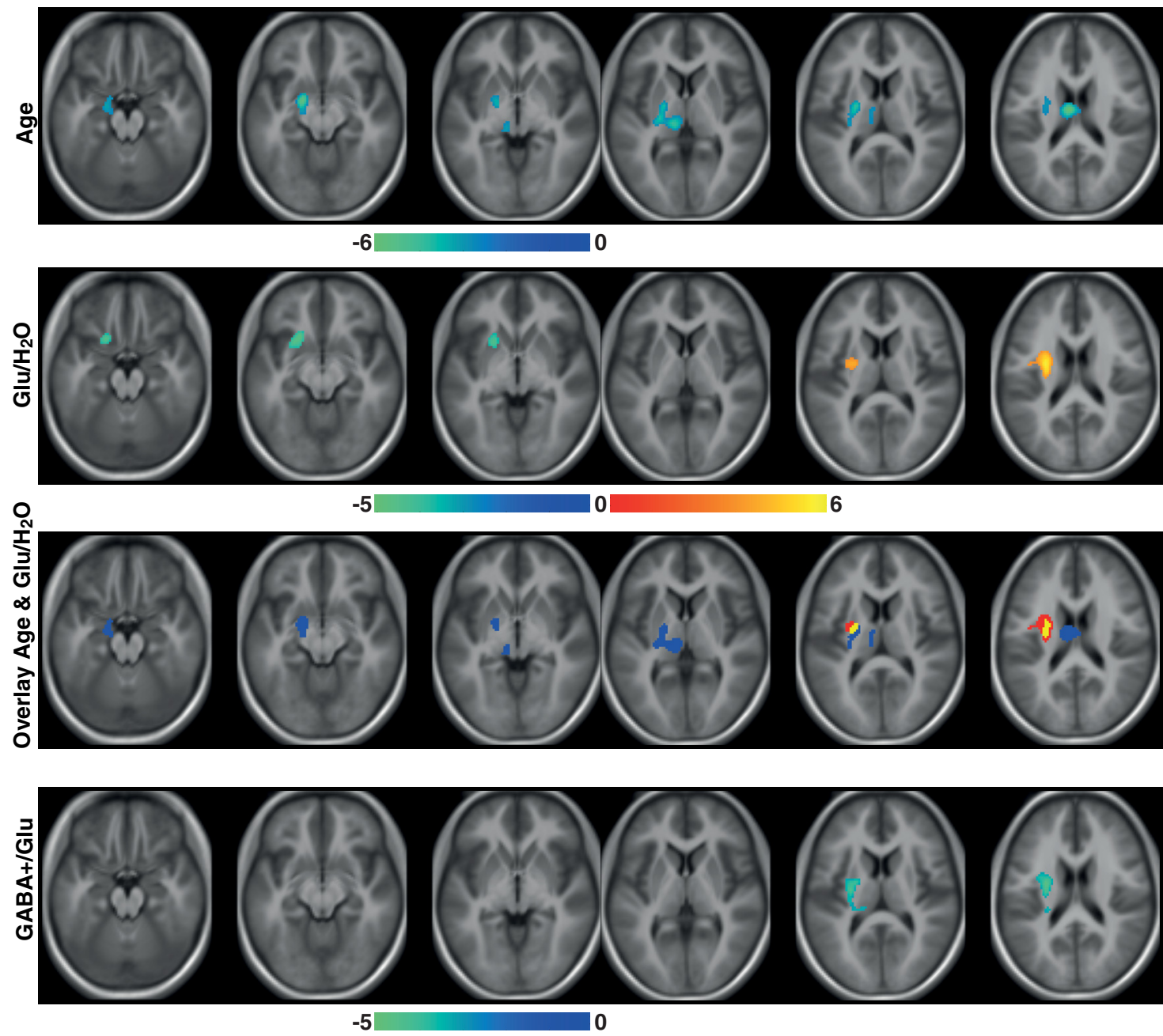

Figure 3. Correlations of functional connectivity (left putamen as seed region) with age, and the spectroscopic measures from the subcortical region. First row, functional connectivity correlated negatively with age in a cluster encompassing the left putamen and neighboring regions, i.e., left pallidum, thalamus, amygdala, hippocampus, and parahippocampal gyrus. Second row, functional connectivity correlated negatively with $\mathrm{Glu} / \mathrm{H}_{2} \mathrm{O}$ in a cluster encompassing the left ventral putamen and orbitofrontal cortex and positively in a cluster encompassing the left dorsal putamen and adjacent external capsule. Third row, overlay of the correlations between functional connectivity and age (blue), $\mathrm{Glu} / \mathrm{H}_{2} \mathrm{O}$ (red), and their overlap (yellow). The cluster showing a correlation with age overlapped in the dorsal putamen with the $\mathrm{Glu} / \mathrm{H}_{2} \mathrm{O}$ correlation cluster but not in other regions such as thalamus or pallidum. Fourth row, functional connectivity correlated negatively with GABA+/Glu values in a cluster encompassing the left dorsal putamen and adjacent external capsule. Results reported survived a height threshold of $p<0.001$ (uncorrected) and an extent threshold of familywise error-corrected $p<0.05$ at the cluster level. Color bar shows $T$ values. Slices are at MNI $z$-coordinates $[-20,-12,-4,4,12,20]$.

Table 2. Correlations of functional connectivity (left putamen as seed region) with age, and the spectroscopic measures from the subcortical region

\begin{tabular}{|c|c|c|c|c|c|}
\hline Correlation & Region & $k$ & $x, y, z(\mathrm{~mm})$ & $T$ & $p$ \\
\hline Age & $\begin{array}{l}\text { Left thalamus } \\
\text { Left pallidum/amygdala /hippocampus } \\
\text { Left putamen/pallidum }\end{array}$ & 1403 & $\begin{array}{l}-6,-12,20 \\
-18,-4,-10 \\
-22,-8,8\end{array}$ & $\begin{array}{l}-6.23 \\
-5.9 \\
-5.34\end{array}$ & $<0.001$ \\
\hline $\mathrm{Glu} / \mathrm{H}_{2} \mathrm{O}$ & Left dorsal putamen and external capsule & 386 & $-28,-6,18$ & 5.85 & 0.024 \\
\hline $\mathrm{Glu} / \mathrm{H}_{2} \mathrm{O}$ & Left ventral putamen/frontal orbital cortex & 330 & $-20,18,-16$ & -4.71 & 0.042 \\
\hline $\mathrm{GABA}+/ \mathrm{Glu}$ & Left dorsal putamen and external capsule & 487 & $-28,-14,16$ & -5.26 & 0.009 \\
\hline
\end{tabular}

Results reported survived a height threshold of $p<0.001$ (uncorrected) and an extent threshold of familywise error-corrected $p<0.05$ at the cluster level. $k$, Cluster size; $x, y, z$ (mm), peak MNI coordinates.

positive and negative correlations between $\mathrm{Glu} / \mathrm{H}_{2} \mathrm{O}$ and functional connectivity in the dorsal and ventral putamen, respectively, suggests a dissociation of the effect of $\mathrm{Glu} / \mathrm{H}_{2} \mathrm{O}$, because only the positive association was related to developmental changes in functional connectivity. We found no significant correlation between connectivity and $\mathrm{GABA}+/ \mathrm{H}_{2} \mathrm{O}$, whereas the association between GABA+/Glu ratio and connectivity across development mirrored the findings from $\mathrm{Glu} / \mathrm{H}_{2} \mathrm{O}$. Other studies reported a negative association between $\mathrm{GABA}+/ \mathrm{H}_{2} \mathrm{O}$ and functional connectivity (Kapogiannis et al., 2013; Stagg et al., 2014).
Those studies included adult subjects only and used other metabolites (i.e., creatine and NAA) for quantification of the GABA values. Note that both NAA and creatine change with age in adults (Haga et al., 2009; Duncan et al., 2014) and in younger $(<18$ years) subjects (Blüml et al., 2013). We used the unsuppressed water signal, which may therefore represent a more stable calibration standard for metabolite quantification in developmental MRS studies.

Glu receptor-mediated synaptic plasticity is a factor in synaptic pruning during brain development and probably involves ad- 
justment of the excitation-inhibition balance on individual neurons and within networks (Selemon, 2013). Variations in this balance might underlie the BOLD signal as an indirect measure of neuronal activity (Logothetis, 2008; Isaacson and Scanziani, 2011; Lauritzen et al., 2012). Our findings concord with studies showing a developmental decrease of local functional connectivity (Fair et al., 2007a, 2009; Supekar et al., 2009), which might be supported by synaptic pruning and myelination (Power et al., 2010). We thus propose that an increase in synaptic pruning during development explains both the lower $\mathrm{Glu} / \mathrm{H}_{2} \mathrm{O}$ and the decrease of local connectivity from childhood to adulthood. The imbalance in the excitation-inhibition ratio has been linked to neurodevelopmental disorders (Gatto and Broadie, 2010) and our work thus is significant in further elucidating the role of Glu in fine-tuning functional connectivity networks.

Several methodological considerations need to be addressed. First, GABA and Glu are present in the brain in different pools (e.g., intracellular vs extracellular levels; Rae, 2014), which cannot be disentangled using current MRS measures. Nevertheless, the concentrations in these pools appear to be balanced, their total measured concentrations are neurophysiologically relevant (Kapogiannis et al., 2013) and any pool may be drawn on as a source for neurotransmitter GABA and Glu (Rae, 2014). Second, it is currently not satisfactorily possible to account for the macromolecular contributions to the GABA signal without compromising data quality or acquisition time (Mullins et al., 2014). Because the macromolecular contribution might be associated with age (Aufhaus et al., 2013), improvements of techniques accounting for this putatively confounding factor are relevant for future developmental studies investigating GABA. Third, agerelated changes in tissue water concentration may also impact the derived water-scaled GABA + and Glu concentrations, but recent developments in relaxometry methods could enable correction for developmental changes in water content in different tissue types in future studies (Kumar et al., 2011). Fourth, this is a cross-sectional study so that inferences on causality of age, metabolite, and connectivity related changes across development need to be investigated in future longitudinal studies. Fifth, we investigated the association between development and metabolites only with relation to the putamen connectivity. Because the acquisition of MRS values take a long time, the frontal voxel was not measured in younger children. This prevented us to directly compare age related changes in putamen connectivity and frontal connectivity. Sixth, both MRS voxels were large so that MRS values might partly be derived from other (gray matter) structures. Although the putamen was the largest structure within the subcortical MRS voxel, we cannot exclude that neighboring or connecting regions contribute to connectivity and to which extent gray or white matter changes with age affect this connectivity. Future studies require examination of the developmental trajectory of metabolites and connectivity in other regions and with comparable voxel sizes for acquiring connectivity and MRS values. Seventh, motion artifacts can bias estimates of functional connectivity, which is particularly important in developmental studies because motion can be related to subject age (Satterthwaite et al., 2013b). Yet, in-scanner motion putatively exerts minimal effects on the present finding of an age-related decrease in local connectivity, because motion appears to affect age-negative connections less strongly than age-positive connections (Satterthwaite et al., 2013b; Chai et al., 2014), and because subcortical areas are among the least affected by head motion because the pivot of head rotation lies near to these regions (Satterthwaite et al., 2013a). Eighth, we used task related background activity to investigate developmental changes in functional connectivity. It has been shown that "hard-wired", i.e., anatomical, connections underlie functional connectivity networks (Damoiseaux and Greicius, 2009), and that task instruction (Norman-Haignere et al., 2012), task performance (Sepulcre et al., 2010), and hormonal concentrations (e.g., oxytocin; Kirsch et al., 2005) can modulate connectivity. The function of ongoing activity is intimately related to cognition, and in both "resting" or active state this relation is inherent to the brain (Sadaghiani et al., 2010). Although the strength of functional connectivity is constrained by structural connectivity, it is modulated by mental states and current context, such that intrinsic activity "constitutes the brain's internal context for processing external information and generating behavior (Kenet et al., 2003; Fontanini and Katz, 2008)" (Sadaghiani et al., 2010, p 12). We thus interpret our functional connectivity findings as representing intrinsic, yet context-dependent background activity and the context was given by our cognitive task. Several studies have reported the positive correlation of Glu also with resting state functional connectivity (Schmaal et al., 2012; Duncan et al., 2013; Kapogiannis et al., 2013). Our results thus extend knowledge by demonstrating this positive correlation also in task-related background activity. We argue that the positive relationship between Glu and functional connectivity is not limited to resting state data, but represents a more general role of Glu in the modulation of functional connectivity. Finally, the putamen has mainly been attributed to filtering efficiency in the context of working memory, i.e., hindering irrelevant information from entering working memory (Frank et al., 2001; McNab and Klingberg, 2008; Baier et al., 2010). The ability to inhibit irrelevant information increases with age (Robert et al., 2009), suggesting a potential role of striatal regions in the development of working memory networks possibly in cooperation with frontoparietal and hippocampal networks (Finn et al., 2010; von Allmen et al., 2014). Our results of lower functional connectivity in striatal regions might reflect the fine-tuning of these filtering processes, possibly mediated by a concomitant lower $\mathrm{Glu} / \mathrm{H}_{2} \mathrm{O}$ across development mirroring increased synaptic pruning. Future studies also investigating other tasks, especially with the addition of irrelevant stimuli, are needed to further elucidate this proposed role of Glu.

In conclusion, we found lower $\mathrm{Glu} / \mathrm{H}_{2} \mathrm{O}$ with age in a subcortical (basal ganglia) voxel and higher $\mathrm{GABA}+/ \mathrm{H}_{2} \mathrm{O}$ with age in a frontal voxel, mirroring higher age-related GABA+/Glu in both regions. We further found lower connectivity between the putamen and other subcortical structures across development. Subcortical Glu $/ \mathrm{H}_{2} \mathrm{O}$ mediated the lower connectivity in the dorsal putamen with age. Given these results and the potential association between Glu and synaptic pruning, we suggest that age related changes in Glu mediate the decrease of local connectivity during development.

\section{References}

Aufhaus E, Weber-Fahr W, Sack M, Tunc-Skarka N, Oberthuer G, Hoerst M, Meyer-Lindenberg A, Boettcher U, Ende G (2013) Absence of changes in GABA concentrations with age and gender in the human anterior cingulate cortex: a MEGA-PRESS study with symmetric editing pulse frequencies for macromolecule suppression. Magn Reson Med 69:317320. CrossRef Medline

Baier B, Karnath HO, Dieterich M, Birklein F, Heinze C, Müller NG (2010) Keeping memory clear and stable: the contribution of human basal ganglia and prefrontal cortex to working memory. J Neurosci 30:9788-9792. CrossRef Medline

Behzadi Y, Restom K, Liau J, Liu TT (2007) A component based noise correction method (CompCor) for BOLD and perfusion based fMRI. Neuroimage 37:90-101. CrossRef Medline 
Blüml S, Wisnowski JL, Nelson MD Jr, Paquette L, Gilles FH, Kinney HC, Panigrahy A (2013) Metabolic maturation of the human brain from birth through adolescence: insights from in vivo magnetic resonance spectroscopy. Cereb Cortex 23:2944-2955. CrossRef Medline

Bonifazi P, Goldin M, Picardo MA, Jorquera I, Cattani A, Bianconi G, Represa A, Ben-Ari Y, Cossart R (2009) GABAergic hub neurons orchestrate synchrony in developing hippocampal networks. Science 326:1419-1424. CrossRef Medline

Bourgeois JP, Rakic P (1993) Changes of synaptic density in the primary visual cortex of the macaque monkey from fetal to adult stage. J Neurosci 13:2801-2820. Medline

Chai XJ, Ofen N, Gabrieli JD, Whitfield-Gabrieli S (2014) Selective development of anticorrelated networks in the intrinsic functional organization of the human brain. J Cogn Neurosci 26:501-513. CrossRef Medline

Chang L, Jiang CS, Ernst T (2009) Effects of age and sex on brain glutamate and other metabolites. Magn Reson Imaging 27:142-145. CrossRef Medline

Damoiseaux JS, Greicius MD (2009) Greater than the sum of its parts: a review of studies combining structural connectivity and resting-state functional connectivity. Brain Struct Funct 213:525-533. CrossRef Medline

Degnan AJ, Ceschin R, Lee V, Schmithorst VJ, Blüml S, Panigrahy A (2014) Early metabolic development of posteromedial cortex and thalamus in humans analyzed via in vivo quantitative magnetic resonance spectroscopy. J Comp Neurol 522:3717-3732. CrossRef Medline

Di Cristo G (2007) Development of cortical GABAergic circuits and its implications for neurodevelopmental disorders. Clin Genet 72:1-8. CrossRef Medline

Duncan NW, Wiebking C, Tiret B, Marjańska M, Hayes DJ, Lyttleton O, Doyon J, Northoff G (2013) Glutamate concentration in the medial prefrontal cortex predicts resting-state cortical-subcortical functional connectivity in humans. PLoS One 8:e60312. CrossRef Medline

Duncan NW, Wiebking C, Northoff G (2014) Associations of regional GABA and glutamate with intrinsic and extrinsic neural activity in humans: a review of multimodal imaging studies. Neurosci Biobehav Rev 47:36-52. CrossRef Medline

Edden RA, Barker PB (2007) Spatial effects in the detection of $\gamma$-aminobutyric acid: improved sensitivity at high fields using inner volume saturation. Magn Reson Med 58:1276-1282. CrossRef Medline

Fair DA, Dosenbach NU, Church JA, Cohen AL, Brahmbhatt S, Miezin FM, Barch DM, Raichle ME, Petersen SE, Schlaggar BL (2007a) Development of distinct control networks through segregation and integration. Proc Natl Acad Sci U S A 104:13507-13512. CrossRef Medline

Fair DA, Schlaggar BL, Cohen AL, Miezin FM, Dosenbach NU, Wenger KK, Fox MD, Snyder AZ, Raichle ME, Petersen SE (2007b) A method for using blocked and event-related fMRI data to study "resting state" functional connectivity. Neuroimage 35:396-405. CrossRef Medline

Fair DA, Cohen AL, Power JD, Dosenbach NU, Church JA, Miezin FM, Schlaggar BL, Petersen SE (2009) Functional brain networks develop from a "local to distributed" organization. PLoS Comput Biol 5:e1000381. CrossRef Medline

Finn AS, Sheridan MA, Kam CL, Hinshaw S, D'Esposito M (2010) Longitudinal evidence for functional specialization of the neural circuit supporting working memory in the human brain. J Neurosci 30:11062-11067. CrossRef Medline

Fontanini A, Katz DB (2008) Behavioral states, network states, and sensory response variability. J Neurophysiol 100:1160-1168. CrossRef Medline

Fox MD, Raichle ME (2007) Spontaneous fluctuations in brain activity observed with functional magnetic resonance imaging. Nat Rev Neurosci 8:700-711. CrossRef Medline

Fox MD, Snyder AZ, Zacks JM, Raichle ME (2006) Coherent spontaneous activity accounts for trial-to-trial variability in human evoked brain responses. Nat Neurosci 9:23-25. CrossRef Medline

Frank MJ, Loughry B, O'Reilly RC (2001) Interactions between frontal cortex and basal ganglia in working memory: a computational model. Cogn Affect Behav Neurosci 1:137-160. CrossRef Medline

Gaetz W, Bloy L, Wang DJ, Port RG, Blaskey L, Levy SE, Roberts TP (2014) GABA estimation in the brains of children on the autism spectrum: measurement precision and regional cortical variation. Neuroimage 86:1-9. CrossRef Medline

Gasparovic C, Song T, Devier D, Bockholt HJ, Caprihan A, Mullins PG, Posse S, Jung RE, Morrison LA (2006) Use of tissue water as a concentration reference for proton spectroscopic imaging. Magn Reson Med 55:12191226. CrossRef Medline

Gatto CL, Broadie K (2010) Genetic controls balancing excitatory and inhibitory synaptogenesis in neurodevelopmental disorder models. Front Synaptic Neurosci 2:4. CrossRef Medline

Giedd JN, Rapoport JL (2010) Structural MRI of pediatric brain development: what have we learned and where are we going? Neuron 67:728-734. CrossRef Medline

Haga KK, Khor YP, Farrall A, Wardlaw JM (2009) A systematic review of brain metabolite changes, measured with $1 \mathrm{H}$ magnetic resonance spectroscopy, in healthy aging. Neurobiol Aging 30:353-363. CrossRef Medline

Harris JJ, Reynell C, Attwell D (2011) The physiology of developmental changes in BOLD functional imaging signals. Dev Cogn Neurosci 1:199_ 216. CrossRef Medline

Isaacson JS, Scanziani M (2011) How inhibition shapes cortical activity. Neuron 72:231-243. CrossRef Medline

Kapogiannis D, Reiter DA, Willette AA, Mattson MP (2013) Posteromedial cortex glutamate and GABA predict intrinsic functional connectivity of the default mode network. Neuroimage 64:112-119. CrossRef Medline

Kenet T, Bibitchkov D, Tsodyks M, Grinvald A, Arieli A (2003) Spontaneously emerging cortical representations of visual attributes. Nature 425: 954-956. CrossRef Medline

Kirsch P, Esslinger C, Chen Q, Mier D, Lis S, Siddhanti S, Gruppe H, Mattay VS, Gallhofer B, Meyer-Lindenberg A (2005) Oxytocin modulates neural circuitry for social cognition and fear in humans. J Neurosci 25:1148911493. CrossRef Medline

Kumar R, Delshad S, Macey PM, Woo MA, Harper RM (2011) Development of T2-relaxation values in regional brain sites during adolescence. Magn Reson Imaging 29:185-193. CrossRef Medline

Lauritzen M, Mathiesen C, Schaefer K, Thomsen KJ (2012) Neuronal inhibition and excitation, and the dichotomic control of brain hemodynamic and oxygen responses. Neuroimage 62:1040-1050. CrossRef Medline

Lebel C, Walker L, Leemans A, Phillips L, Beaulieu C (2008) Microstructural maturation of the human brain from childhood to adulthood. Neuroimage 40:1044-1055. CrossRef Medline

Logothetis NK (2008) What we can do and what we cannot do with fMRI Nature 453:869-878. CrossRef Medline

McNab F, Klingberg T (2008) Prefrontal cortex and basal ganglia control access to working memory. Nat Neurosci 11:103-107. CrossRef Medline

Michels L, Martin E, Klaver P, Edden R, Zelaya F, Lythgoe DJ, Lüchinger R, Brandeis D, O'Gorman RL (2012) Frontal GABA levels change during working memory. PLoS One 7:e31933. CrossRef Medline

Mullins PG, McGonigle DJ, O'Gorman RL, Puts NAJ, Vidyasagar R, Evans CJ, Edden RA (2014) Current practice in the use of MEGA-PRESS spectroscopy for the detection of GABA. Neuroimage 86:43-52. CrossRef Medline

Norman-Haignere SV, McCarthy G, Chun MM, Turk-Browne NB (2012) Category-selective background connectivity in ventral visual cortex. Cereb Cortex 22:391-402. CrossRef Medline

Østby Y, Tamnes CK, Fjell AM, Westlye LT, Due-Tønnessen P, Walhovd KB (2009) Heterogeneity in subcortical brain development: a structural magnetic resonance imaging study of brain maturation from 8 to 30 years. J Neurosci 29:11772-11782. CrossRef Medline

Paus T, Keshavan M, Giedd JN (2008) Why do many psychiatric disorders emerge during adolescence? Nat Rev Neurosci 9:947-957. CrossRef Medline

Power JD, Fair DA, Schlaggar BL, Petersen SE (2010) The development of human functional brain networks. Neuron 67:735-748. CrossRef Medline

Provencher SW (1993) Estimation of metabolite concentrations from localized in vivo proton NMR spectra. Magn Reson Med 30:672-679. CrossRef Medline

Rae CD (2014) A guide to the metabolic pathways and function of metabolites observed in human brain $1 \mathrm{H}$ magnetic resonance spectra. Neurochem Res 39:1-36. CrossRef Medline

Robert C, Borella E, Fagot D, Lecerf T, de Ribaupierre A (2009) Working memory and inhibitory control across the life span: intrusion errors in the reading span test. Mem Cognit 37:336-345. CrossRef Medline

Rodriguez M, Sabate M, Rodriguez-Sabate C, Morales I (2013) The role of non-synaptic extracellular glutamate. Brain Res Bull 93:17-26. CrossRef Medline

Sadaghiani S, Hesselmann G, Friston KJ, Kleinschmidt A (2010) The rela- 
tion of ongoing brain activity, evoked neural responses, and cognition. Front Syst Neurosci 4:20. CrossRef Medline

Sailasuta N, Ernst T, Chang L (2008) Regional variations and the effects of age and gender on glutamate concentrations in the human brain. Magn Reson Imaging 26:667-675. CrossRef Medline

Satterthwaite TD, Elliott MA, Gerraty RT, Ruparel K, Loughead J, Calkins ME, Eickhoff SB, Hakonarson H, Gur RC, Gur RE, Wolf DH (2013a) An improved framework for confound regression and filtering for control of motion artifact in the preprocessing of resting-state functional connectivity data. Neuroimage 64:240-256. CrossRef Medline

Satterthwaite TD, Wolf DH, Ruparel K, Erus G, Elliott MA, Eickhoff SB, Gennatas ED, Jackson C, Prabhakaran K, Smith A, Hakonarson H, Verma R, Davatzikos C, Gur RE, Gur RC (2013b) Heterogeneous impact of motion on fundamental patterns of developmental changes in functional connectivity during youth. Neuroimage 83:45-57. CrossRef Medline

Schmaal L, Goudriaan AE, van der Meer J, van den Brink W, Veltman DJ (2012) The association between cingulate cortex glutamate concentration and delay discounting is mediated by resting state functional connectivity. Brain Behav 2:553-562. CrossRef Medline

Selemon LD (2013) A role for synaptic plasticity in the adolescent development of executive function. Transl Psychiatry 3:e238. CrossRef Medline

Sepulcre J, Liu H, Talukdar T, Martincorena I, Yeo BT, Buckner RL (2010) The organization of local and distant functional connectivity in the human brain. PLoS Comput Biol 6:e1000808. CrossRef Medline

Silveri MM, Sneider JT, Crowley DJ, Covell MJ, Acharya D, Rosso IM, Jensen JE (2013) Frontal lobe $\gamma$-aminobutyric acid levels during adolescence: associations with impulsivity and response inhibition. Biol Psychiatry 74:296-304. CrossRef Medline

Stagg CJ, Bachtiar V, Amadi U, Gudberg CA, Ilie AS, Sampaio-Baptista C, O'Shea J, Woolrich M, Smith SM, Filippini N, Near J, Johansen-Berg H (2014) Local GABA concentration is related to network-level resting functional connectivity. eLife 3:e01465. CrossRef Medline

Supekar K, Musen M, Menon V (2009) Development of large-scale functional brain networks in children. PLoS Biol 7:e1000157. CrossRef Medline

Träber F, Block W, Lamerichs R, Gieseke J, Schild HH (2004) 1H metabolite relaxation times at 3.0 tesla: measurements of $\mathrm{T} 1$ and $\mathrm{T} 2$ values in normal brain and determination of regional differences in transverse relaxation. J Magn Reson Imaging 19:537-545. CrossRef Medline

Vélez-Fort M, Audinat E, Angulo MC (2012) Central role of GABA in neuron-glia interactions. Neuroscientist 18:237-250. CrossRef Medline

von Allmen DY, Wurmitzer K, Klaver P (2014) Hippocampal and posterior parietal contributions to developmental increases in visual short-term memory capacity. Cortex 59:95-102. CrossRef Medline

Whitfield-Gabrieli S, Nieto-Castanon A (2012) Conn: a functional connectivity toolbox for correlated and anticorrelated brain networks. Brain Connect 2:125-141. CrossRef Medline

Zaaraoui W, Fleysher L, Fleysher R, Liu S, Soher BJ, Gonen O (2007) Human brain-structure resolved $\mathrm{T} 2$ relaxation times of proton metabolites at 3 tesla. Magn Reson Med 57:983-989. CrossRef Medline

Zhang S, Hu S, Bednarski SR, Erdman E, Li CS (2014) Error-related functional connectivity of the thalamus in cocaine dependence. Neuroimage Clin 4:585-592. CrossRef Medline 